\title{
12 Assisted reproduction with donated eggs and sperm: A comparison of regulations on assisted reproduction in Norway and Japan
}

\section{Merete Lie and Yukari Semba}

\section{Assisted reproduction in Norway and Japan}

Assisted reproductive technologies (ARTs) spread globally after the first birth by in vitro fertilisation (IVF) took place in the UK in 1978. IVF is a process of fertilisation, whereby an egg is combined with sperm outside the body, in vitro. The first IVF baby was called a 'test-tube baby' (Van Dyck, 1995) and the term from their initial introduction was 'artificial reproduction.' Opponents warned against ARTs on the grounds that reproduction constituted the very basis of humanity and that scientists were 'playing God.' Moreover, ARTs go to the core of gender distinction as it is understood as based in sexual reproduction. Despite these controversies, ARTs were rapidly and eagerly adopted. This led to advances in reproductive science and practice which, in turn, resulted in new methods and more efficient practices. As the very same reproductive technologies rapidly spread globally, controversy generally followed. However, the arguments proposed in the ensuing debates, especially the weight given to various arguments, differed across nations (e.g., Inhorn \& van Balen, 2002; Lie \& Lykke, 2017). By looking comparatively at the cases of Japan and Norway, we investigate the localised nature of the ART debate.

In this chapter, we will compare the regulations of ARTs in two nations that differ culturally and socially - both historically and in contemporary times. According to Jasanoff (2005), regulations governing emerging life sciences have been incorporated into national projects to proclaim the basic values of a nation. These may be as varied as being in the frontline of science and progress versus fronting strict regulations substantiated in cultural values or religion. When ARTs were introduced in the UK, for example, values prominent during the Thatcher era, such as the promotion of a new enterprise culture and the value of individual consumer choice, constituted the framework of the political debate (Franklin, 1997). In the US, however, as Becker (2000) pointed out, the conservative notion of family values was the moral authority underlying the debate. In Norway, the political debate was grounded in the pillars of the welfare state, the belief in 


\section{2}

technology and progress, and a widely shared value of gender equality (Spilker \& Lie, 2007). In Japan, Dr. Masakuni Suzuki, who successfully conducted the country's first IVF in 1983 at Tohoku University, argued that IVF technology would help many people suffering from infertility and ultimately help the country by enabling the procreation of new citizens (Yui, 2016).

To compare the responses to ARTs in Japan and Norway, the chapter poses two key questions. Firstly, what are the differences and similarities in the regulations of ARTs - that is, what is permitted and for whom? Secondly, how are the regulations justified, and what does such a justification say about the two countries' basic values and cultural differences in the late 20th and early 21st centuries? Public discourse and policy - that is, the debates and decisions on these matters - comprise our source material for discussing how meaning and morality are articulated in relation to gender and reproduction in the two countries.

\section{Theoretical perspectives}

This chapter frames our investigation of ARTs in Japan and Norway by focusing on a comparison of the regulations of gamete donation in the two countries. This is one of the many intriguing ART fields whereby one and the same technology functions differently across cultures. This has inspired Science, Technology and Society (STS) research on the social and cultural aspects of technologies and their technical development as well as crosscultural studies among anthropologists.

Regarding STS research, Jasanoff (2005) argues that cross-state comparisons often have the aim of determining best practices and policies by learning from other countries. According to Jasanoff, however, the problem here is twofold. One is that national policies are not independent of local cultural and social factors; inevitably, cultural differences trickle into policy making. Even when policymakers in different countries lean on similar data and scientific arguments, these may be interpreted differently or given different weight depending on the local context (Jasanoff, 2005, p. 17). Moreover, the same policies will not function in the same way in the environments in which they are introduced, and their effects will vary accordingly.

Research in medical anthropology underscores Jasanoff's position. Crosscultural studies in this field elaborate differences that reveal the inherently local and political nature of biomedicine and biotechnology (Adelson et al., 2013). Moreover, not only may health services and medical training differ among nations but also symptoms and diseases within populations. For instance, Lock (1993) examines women's experience of menopause and finds striking differences between Japan and the US. In the US, menopause is experienced as a major physical transition characterised by well-known symptoms such as hot flashes. In Japan, however, menopause is not regarded as a major life event but 
part of an ongoing process towards ageing; stiff shoulders are reported but seldom are hot flashes (Lock, 1993). Thus, the experience of bodily symptoms can hardly be discerned from a single society's expectations for health and illness. Similarly, national health services organised to care for the population build on such expectations.

Globalisation means that science and technologies, as well as people and cultural influences, are increasingly travelling across borders. Nevertheless, similar influences may meet a variety of responses (Inda \& Rosaldo, 2008). Therefore, anthropologists hold that comparisons should be locally embedded and not pretend to hold a disembodied 'gaze from nowhere' (Haraway, 1988). As the same phenomenon does not signify the same within different contexts, anthropologists argue against making crosscultural comparisons out of context and argue for making comparisons only when they are locally embedded (Gingrich \& Fox, 2002). Moreover, in anthropological studies comparison occurs also more implicitly as one inevitably will use one's own background as reference when investigating similar phenomena in other countries. Our advantage is that each author's point of departure is the knowledge of their own country.

The chapter focuses on the case of assisted reproduction with donated gametes (eggs and sperm). The data material consists of official government documents, official announcements, reports from professional groups and Parliamentary debates, and information from news media on political debates on this issue in Japan and Norway. Because of different developments in the two countries - such as legalisation versus guidelines and the relative power of the Parliamentary representatives versus professional organisations - the emphasis on the use of different types of data differs in the analyses of Japan and Norway. In the analyses, we identify instances of socially and culturally grounded reasoning that frame the pro-and-con arguments of gamete donation in the two countries. What arguments and by whom have passed as relevant and legitimate, and on what grounds did both countries shift from long-term restrictions to the recent permission of egg donation?

In the following, we will analyse this development over time in each country and study the debates and decision-making as processes of cultural production. As debates and policies vary, these sections will focus partly on the same issues and partly on different ones. This examination leads to our discussion of similarities and differences in ART regulations and arguments in the pro/con debates in the two countries.

\section{ART regulations in Japan}

\section{Sperm donation}

The history of ART in Japan dates back to the late 1940s. In 1948, Dr. Kakuichi Ando of the Medical School in Keio University, Tokyo, 


\section{4}

initiated donor insemination (DI) procedures at the request of a couple suffering from male infertility. The first DI baby was born in 1949 in Japan. Since then, more than between 10,000 and 15,000 DI offspring are estimated to have been born (Minami, 2016). Dr. Ando faced severe disapproval after news of the first DI baby became public. However, he defended his decision as necessary for helping a legally married infertile couple. In Japanese culture, the eldest son traditionally took on the mantle of head of household and was expected to perpetuate the family name. Thus, the eldest male progeny and his wife were expected to bear children regardless of circumstances (Castro-Vàzquez, 2017). This emphasis on paternal duty shaped DI in Japan as an important means of protecting the masculinity of infertile men, whether or not they were fathers in genetic terms. DI was also beneficial for women because the majority of people at the time ascribed the fault of infertility to the wife. Not only did this assumption devalue the childless wife, but it also threatened her marriage (Takeya, 2008). If a couple was unable to bear a child, then continuing the marriage became difficult for them. Hence, DI became acceptable due to public sympathy for infertile couples.

Thus, sperm donation has been practised since the 1940s, and the first commercial sperm bank in Japan was established in 1996. Subsequently, in 1997, Japan Society of Obstetrics and Gynecology (JSOG) established its first guidelines pertaining to DI, which stipulated that the technique should only be offered to legally married couples, that the wife and husband should tender informed consent and that the commercial provision of the donated sperm to infertile couples should be prohibited. Since 2018, however, fear of identity disclosure has led to a decrease in the number of anonymous sperm donors. One hospital cautioned potential sperm donors about the possibilities of identity disclosure in the informed consent form. The form stated that their anonymity might be in jeopardy if a donor offspring initiated legal action at any time in the future to demand the disclosure of the donor's identity and personal information (Osaki, 2020). This decrease has meant that people in Japan with infertility who are seeking to conceive through donated sperm are likely to go abroad or turn to online sperm donation (Kobayashi et al., 2020).

\section{Egg donation}

The first IVF baby in Japan was born in 1983. ARTs accounted for 5.8\%, or 1 in 16.7, of all babies born in Japan in 2017 (Katagiri, 2020). Despite the substantial application of ARTs, no laws or legal regulations regarding ARTs existed until recently in Japan. Third-party reproduction has been governed by the guidelines established by the JSOG. Under JSOG guidelines, clinics could only utilise IVF with legally married couples. They could not assist women with becoming egg donors for other women. However, these guidelines are not legally binding, meaning that clinicians can 
continue their medical careers even if they violate them. The first case of IVF using donated eggs in Japan was publicly disclosed in 1998. Dr. Nezu Yahiro had performed IVF using eggs donated by a wife's sister, leading to him later being temporarily expelled from JSOG for violating its guidelines (Kinjō, 2012). There are also numerous instances of couples traveling overseas to seek donated eggs because they could not get donated egg in Japan.

In response to the first domestic egg donation case and the rise of Japanese couples seeking donated eggs abroad, the former Ministry of Health and Welfare (currently the Ministry of Health, Labour and Welfare) established the ART Committee in June 2001 to discuss the drafting of a new bill on third-party reproduction (Tsuge, 2005). In 2003, the ART Committee concluded that reproductive medicine using donated gametes should be permitted, that treatments using gametes of siblings or other relatives should be prohibited and that the offspring should be accorded the right to acquire donor information. However, no law incorporating the Committee's conclusions had been enacted at this time.

The Japanese Institution for Standardizing Assisted Reproductive Technology (JISART), established in 2003, is an organisation that regulates the standards and practices of ART clinics with the aim of achievement of high standards of practice of infertility management. According to its bylaws, JISART aims to improve the quality of patient care through the implementation of a quality management system in Japan. Since 2007, clinics registered as members of JISART perform IVF using donated eggs after acquiring requisite approvals from the JISART's ethics committees (JISART, 2021).

The Oocyte Donation Network (OD-Net) was established in Japan in August 2012 with the objective of helping women with congenitally reduced ovarian functions (e.g., Turner syndrome) as well as prematurely menopausal women. OD-Net began to recruit voluntary egg donors and launched Japan's first egg bank in 2013. OD-Net's stipulations for donor candidates requires that the women are under 35 years of age, have previously given birth, are a good match for recipients in medical terms, have consent from their husbands to register as donors, would provide their eggs free of charge, and are willing to disclose their identities if the donorconceived child requires it upon reaching the age of 15. OD-Net reported that the first child conceived by using donated eggs from an anonymous volunteer egg donor was born in 2017. However, it is still hard to find egg donors in Japan. So, certain countries in south and southeast Asia, such as India, Thailand, Vietnam, Laos, Nepal, and Cambodia, were destinations for Japanese fertility tourists seeking donated eggs. Most of these nations have recently banned the provision of eggs to foreign clients due to problems related to donor conception. Therefore, Some Japanese couples travel to Eastern Europe, Russia and the US, for this purpose ('Score of life,' 2014). 


\section{Legalisation of gamete donation}

Male infertility has been regarded as a more serious crisis than women's infertility because the husband's bloodline has long been viewed as more important in Japan. Many infertile men have confessed that their inability to father children made them feel that they had no value because they did not live up to the male gender role (Kurahashi, 2017). Thus, DI was introduced to simultaneously alleviate male anxiety and mask male infertility. Nevertheless, women without children still face prejudice and discrimination, bearing the stigma of assumed infertility.

A 2014 survey of public attitudes towards third-party reproduction in Japan revealed a notable division: $36.2 \%$ of respondents considered gamete or embryo donations as socially acceptable, whereas $26.6 \%$ found them unacceptable (Yamamoto et al., 2018). Although the demand for egg donation is expected to increase in Japan as women marry later in life and incidences of age-related infertility increase, some barriers remain in place such as egg donors may incur risks such as ovarian hyperstimulation syndrome or damage to ovaries caused by egg retrieval for another woman. In $2018,99 \%$ of hospitals and clinics performing IVF in Japan refrained from facilitating egg donations because of JSOG's guidelines (Shirai, 2019).

On 4 December 2020, the Japanese Diet (Parliament) passed Seishoku Iryō Minpō Tokureihō (Reiwa 2 nen hōritsu dai 76 gō [Reproductive Medicine Civil Code Special Law (2020 Law No. 76)]), which recognised the legal parenthood of married couples who bore children through donated eggs and sperm. Sperm donor shortage had become a serious issue since the beginning of the 21 st century. It was thought that fewer men were willing to donate their sperm once they learned of the increasing legal rights of children globally to contact their biological parents (Robertson, 2018). Thus, the new ART law defines the parentage of children born through ARTs using donated gametes, and, in March 2021, both sperm donation and egg donation became legal in Japan under the special ART law. The main objective of the law is to stabilise the legal status of children born through third-party reproduction. The law stipulates that children born through egg or sperm donation will legally be the children of the birth mother and the mother's husband who agreed to the use of the donated eggs and sperm. However, the law does not address the use of donated gametes by same-sex women couples and single women, only that by opposite-sex couples. This is a strong example of lawmakers' attachment to the traditional view of the family as composed of heterosexual parents and their children. Meanwhile, additional clauses in Reproductive Medicine Civil Code Special Law in 2020 state that 'necessary legal measures will be taken within a target of roughly two years' regarding the right of the donorconceived children to know their donors. Although donor anonymity is an important issue in many countries, it cannot be preserved in any case, given the current availability of genetic testing and tracing (Harper et al., 2016). 
Moreover, the law does not cover other pressing issues, such as commercial gamete donation and surrogacy. The 2021 law nonetheless does reflect anxiety over Japan's aging population and declining birth rate, and it is congruent with the national objective of promoting childbirth (Wernick, 2020).

\section{ART regulations in Norway}

Norway was an early initiator of legal regulations governing ARTs, having implemented them as early as 1987 . Until recently, its legal regulations have been among the strictest in the world (Bleikli et al., 2004; Engeli \& Allison, 2017). However, a radical turn occurred in 2020 when the Parliament voted in favour of egg donation, access to fertility treatments for single women and egg freezing without medical reasons. Whereas previously a need for caution had been the winning argument for change, now the main argument was that a modern society should make use of technologies once they are available and follow up on those under development.

This section will cover the development of ART regulations in Norway. Norway has a comprehensive public health service offering medical examination and three free IVF trials, initially for only heterosexual couples but later also offered to same-sex women couples and single women. Private clinics provide fertility treatments but require clients to pay for the treatments; the related drugs are subsidised by the state.

As in Japan, debate over ART in Norway goes back to the 1950s. In the early 1950s, a debate on DI surfaced after the appointment of a committee tasked with evaluating the practice and the legal status of the resulting offspring. The report resulted in a sharp debate in which opponents of the practice argued that donor sperm morally undermined the very essence of marriage by allowing a third person into the parental relationship (Melhuus, 2012). ${ }^{1}$ Nevertheless, no ban on insemination with donor sperm was introduced.

Heated debates started again after the birth of the first IVF babies, in England in 1978 and in Norway in 1984. Three years later, in 1987, the first legal regulation, entitled Law on Artificial Conception, was introduced in Norway. In 1994, new ART regulations were included in the more comprehensive Law on Medical Use of Biotechnology. Although the 1987 law permitted sperm donation, it prohibited egg donation. In 1994, however, an amendment to the law allowed for egg donation for those with certain medical conditions.

ARTs remained politically controversial. The term used for the techniques was artificial fertilisation, and, in media debates, practitioners were accused of tampering with nature. During the 1990s, to avoid stigmatising parents and their IVF children, the official term was set as 'assisted fertilisation.' In 2002, the government headed by the right-wing Christian Democratic Party - the political party most engaged in these issues brought about a Parliamentary debate on revision of the 1994 law. Access 
to egg donation, the most controversial issue at the time, had many supporters but not enough to win the majority. The vote in the Parliament resulted in an even stricter law. Egg donation remained prohibited, supported by the argument that there should be no doubt as to the identity of the child's mother. Moreover, it was voted in favour of upheaval of anonymity of sperm donors with reference to the child's right to know its origin.

In the 2002 debate, the Labour Party framed the issue of egg donation as a question of gender equality, arguing that if sperm donation is legal, then egg donation should likewise be allowed. Since gender equality is highly valued in Norway, the ban on egg donation was posed as a denial of gender equality. A representative from the conservative political party Høyre (The Right) countered this supposition by stating a limit to gender equality based on biological difference: 'Not everything can, or should, be made equal' (Spilker \& Lie, 2007, p. 335). Norway follows the traditional Roman law, Mater semper certa est (motherhood is always certain); thus, a mother is legally defined as the person who gave birth to a child. However, legal fatherhood is defined in social terms as the man who is married to the woman who gives birth (Pater est quem nuptiae demonstrant). In the debate, gender emerges as highly relevant in the bioethical debate with gametes as a form of stand-in for women and men and their respective sexual behaviours. Politicians argued that whereas eggs remain in a woman's body, sperm had always 'gone astray,' pointing to men's extramarital sexual behaviour. However, egg cells should remain with the birth mother, and it was essential to avoid raising doubts about the identity of the mother.

From 2003 to 2020, the Law on Medical Use of Biotechnology remained in effect with two exceptions. In 2007, same-sex couples received access to treatment. This was a consequence of changing the law of marriage by granting same-sex couples equal legal rights to heterosexual couples. Later, access was granted to couples where one person has a heritable venereal disease, such as HIV. Thus, no longer was a couple's infertility the only qualification for ART. The law continued to gradually loosen until a revision in 2020 instantly changed the Norwegian Biotechnology Act from one of the strictest in the world to a relatively liberal one. Egg donation was legalised along with fertility treatment for single women. The law also permitted egg freezing without medical reasons and access to early ultrasound examination ${ }^{2}$ and NIPT (non-invasive pre-natal) testing for all pregnant women. Nevertheless, certain restrictions were added, such as an age limit of 46 years for a woman to gain access to ARTs. Egg donation was limited to couples where one parent would have a genetic relation to the offspring. Parents were obliged to tell children that they were conceived via a donor, and the age for children to ask for information about donors was lowered from 18 years to 15 years.

Returning to public discourse on ARTs, we find that Parliamentary debate in 2020 emphasised arguments that affirmed Norway's status as an 
up-to-date society and a gender equal one. Firstly, lawmakers argued in favour of liberalising the law on the grounds that the technology had developed and matured. To be a modern society, they argued, Norway should permit and use these technologies. Secondly, they contended that these changes meant acknowledging women's fertility rights. Many of the speakers supported the argument that Norway needed a modern Biotechnology Act to uphold the value of giving the population access to modern medical treatments. Previously, the principal concern of the Norwegian Biotechnology Act has been precautionary, employing a 'better safe than sorry' approach so long as the consequences remain unknown (Melhuus, 2012). However, the most persuasive arguments in 2020 was the need to update and remain in the frontline of global technological developments. Thus, the Parliament voted in favour of a suggestion that the law should be continually reviewed and updated to adapt to rapid developments in biotechnology.

There was a debate on restrictions regarding the use of surrogacy abroad among Norwegian citizens, but this suggestion was not approved. The prohibition of surrogacy, however, was retained with a clear majority. Moreover, the government was urged to work in international fora 'against the abuse of women in the international surrogacy industry. ${ }^{3}$

The importance of notions of gender equality differed in 2002 and 2020. In 2002, for example, support for egg donation as a matter of gender equality failed to win the majority. At the time, the vote against egg donation was based on a partially forthright and partially implicit assumption about the priority of motherhood, which worked against equalising egg and sperm donation. The 2020 debate, however, did not frame equality as a matter of gender but as a question of access to treatments within the public health service. This position argued that all women regardless of income and location must be provided access to such specialised health services. The argument of equal access also included the aim of putting an end to the so-called fertility travel abroad. Access to available fertility treatments and tests were presented as women's rights, whereas men were seldom mentioned in the debate. Only a few representatives spoke against fertility treatment for single women by arguing that children need fathers. This lack of debate about fatherhood and support for single motherhood was slightly surprising given the long campaign to acknowledge the equal importance of fatherhood and motherhood as part of gender equality policies in Norway. Legally and culturally, Norway has a bilateral kinship system, acknowledging genetic as well as economic and social inheritance from both sides.

The 2020 debate in Norway's Parliament illuminated how ART regulations are considered ethical and political questions, guided by the perceptions and politics of gender. During the debates, there was hardly any reference to medical expertise or consideration of advice from the officially appointed Biotechnology Advisory Board. ${ }^{4}$ Rather, the debate mainly centred on differing values and morals among the lawmakers. Before the 
vote, a major newspaper in Norway conducted a survey on the question of egg donation and found that $57 \%$ of respondents were in favour of legalising the practice. ${ }^{5}$ Furthermore, young people were more positive about egg donation than older people were. Among the adherents of different political parties, those voting for the left were most positive; only those voting for the Christian Democratic Party had a clear majority against egg donation. In 2002, the conservative party Høyre had argued against egg donation based on the primacy of motherhood and the importance of never questioning the identity of the mother. In 2020, however, they argued in favour of egg donation when the arguments had shifted to individual rights for access to available treatments. The recent legal permissiveness may also be due to the rapid decrease in Norway's fertility rate and an appeal from the conservative Prime Minister for the nation to making more babies (cf. Chapter 11 in this book).

\section{Egg and sperm across nations: Similarities and differences}

Human reproduction is closely associated with gender norms, sexuality, family patterns and kinship. Hence, cultural differences most visibly surface in these areas during the debates and regulations of ARTs.

In both Japan and Norway, a marked divide has existed between the legality of sperm donation versus the prohibition on egg donation. Although sperm donation has been practiced for a long time and included in the health services of both countries, IVF using donated eggs was prohibited in Norway and Japan until 2020 and 2021, respectively. In Norway, DI was controversial but publicly recognised when it became part of the national health service in 1972. In 2005, the donor anonymity clause was rescinded, based on the belief in a child's right to know its origin. In Japan, DI was introduced in 1948, causing some controversy but rapidly coming into use. The Japanese special ART law came into effect in March 2021 and stated that 'necessary legal measures will be taken within a target of roughly two years' regarding the right of donor-conceived people to know their donors. DI has continued retaining the practice of allowing anonymous sperm donors, and many voices have been raised in Japan against the abolition of donor anonymity to protect the masculinity of infertile men and donors' privacy.

The two countries differ in terms of the recognition of kinship. In Japan, kinship is recognised traditionally through the father-line, which makes producing a male progeny of utmost importance to couples and their extended families. In Norway, kinship is recognised bilaterally. Research shows that in countries where sperm donation is viewed as less acceptable, the male line is recognised as the sole inheritance line; this contrasts with countries where acknowledgement of the mother's line is more important than that of the father (Inhorn \& van Balen, 2002; Mehrabi, 2017). Still, in both Japan and Norway, 
sperm donation is less controversial than egg donation, which accords with the overriding principle that motherhood should never be questioned.

In both countries, women are culturally recognised as protagonists in terms of reproduction. It is generally taken for granted that women want children, and only those without children have to explain themselves to others (Ravn, 2005). In Norway, this was reflected in the latest Parliamentary debate, as discussed above, where ARTs were framed as part of the reproductive rights of women. In Japan, infertility was generally understood as caused by a barren woman, while infertility among men was silenced. Thus, if a couple failed to bear children, then a culturally approved remedy was for a man to divorce and remarry. As such, anonymity contributed to the silencing of male infertility when sperm donation became a practice.

A marked difference between attitudes toward ARTs in the two countries relates to the cultural norms of maintaining reproduction exclusively within marriage. In Japan, fertility treatments are offered to heterosexual married couples only. At the core, Japan has a family pattern that emphasises the birth of a son in the patrilineal system and within the bounds of legal marriage. Thus, increasingly later marriages in contemporary Japan have led to concerns about the rise of childless couples. Moreover, male infertility is a problem that is both silenced as if non-existent, and a matter of great concern. In Norway, however, childbirth likewise has been postponed during the last decades but is not in the same way connected to legal marriage or the patriline. ${ }^{6}$ Consequently, in Japan, access to ARTs is restricted to childless married couples, whereas, in Norway, unmarried couples, same-sex women couples and single women have gained access to ARTs on equal terms over time.

Egg donation had, however, been prohibited in both countries until very recently. A striking similarity between the two countries is that they recently and at the same time took a radical step in moving from restrictive to permissive regulations. The arguments in favour of such a change are simultaneously similar and different. In Japan, the central arguments lie in the low birth rate and the many couples who travel abroad for treatments that are inaccessible in their country. In the context of an ageing population and a declining birth rate, allowing IVF using donated eggs is congruent with the objective of the country to promote childbirth. The legal approval of gamete donation, including eggs, is viewed as a countermeasure to the declining birth rate. Lawmakers and politicians have never argued for access to donated gametes as an issue of gender equality or human rights. Little attention is paid to the welfare of donor-conceived children or the right of same-sex women couples and single women to bear children. Thus, ART access remains denied to them.

In Norway, the argument that the country needs more children was also valid in the 2020 Parliamentary debate, but more emphasis was given to women's individual rights for access to treatments that are available 


\section{2}

worldwide. Moreover, access to ART treatments, including egg and sperm donation, was extended to single women following the earlier extension to same-sex women couples. The overall arguments in the Parliamentary debate was centred on the goal of becoming a modern country by utilising available technologies instead of lagging behind, and that all women should have the right to access these technologies equally within the public health system.

In both countries, the argument for permissive regulations of gamete donation aims to put an end to fertility travel outside of the country to gain access to treatments that are not permitted in one's country. Interestingly, the argument that the treatments are safer in one's country than abroad is equally argued in Japan and Norway.

Finally, an interesting point of comparison is that when Norway included ART regulations under the new and more comprehensive Law on Medical Use of Biotechnology in 1994, the first paragraph states its purpose as follows:

The purpose of this Act is to ensure that the application of biotechnology in medicine is utilised in the best interests of human beings in a society where everyone plays a role and is fully valued. This shall take place in accordance with the principles of respect for human dignity, human rights and personal integrity and without discrimination on the basis of genetic background, on the basis of ethical norms relating to our western cultural heritage. [emphasis added] ${ }^{7}$

The Parliament reached a consensus in 1994 that the law should be based on ethical principles (as opposed to medical or scientific reasoning) and primarily on the principle of the equal value of all human beings. After the rejection of a proposal on Christian values, the voters then reached an agreement on the statement 'our western cultural heritage' (Melhuus, 2012, p. 63). An actual definition of this heritage was not included in the statement; neither does it refer to a long-lasting debate about Eastern versus Western values (see, e.g., Wong, 2008). The Japanese ART law does not include similar general statements.

As previously mentioned, ARTs refer to technologies that are accessible across the world. In discussions of globalisation, there has been a continuous debate on the relationship of global trends versus local cultures and traditions, including arguments of eastern and western values versus the idea of 'universal human values' (Inda \& Rosaldo, 2008). Some have argued that in a time of increasing global exchange there is a need for global ethics, but still, the case of ART regulations reveals marked differences between nations (Bleikli et al., 2004). Japan and Norway differ according to their cultural traditions of family patterns, kinship and gender relations. Nonetheless, when analysing the debates and policies of gamete donation, an overall argument is that policies of egg and sperm donation have differed 
over time due to cultural understandings of a basic gender difference - an argument that is similar in both countries.

\section{Notes}

1 See Melhuus (2012, pp. 47-70) for a thorough analysis of the Norwegian legislation of ARTs until 2011.

2 Until 2020, all pregnant women were offered an ultrasound examination by week 18 , that is, after the limit of free abortion at week 12. In addition, the Parliament requested the government to enforce access to ultrasound examinations during the first trimester and within the public health service system.

3 https://www.stortinget.no/no/Saker-og-publikasjoner/Vedtak/Vedtak/Sak/?p= 77395. Vedtak 621.

4 Retrieved from https://www.bioteknologiradet.no/english/ (accessed 5 November 2020).

5 Retrieved from https://www.aftenposten.no/norge/politikk/i/zJ3E4/klart-flertallsier-ja-til-aa-aapne-for-eggdonasjon-i-norge (accessed 5 November 2020).

6 Retrieved from https://www.ssb.no/en/statbank/list/fodte (accessed 30 November 2020).

7 Retrieved from https://app.uio.no/ub/ujur/oversatte-lover/data/lov-19940805056-eng.pdf (accessed 30 November 2020). Italics inserted by authors.

\section{References}

Adelson, N., Butt, L., \& Kielman, K. (Eds.). (2013). Troubling natural categories: Engaging the medical anthropology of Margaret Lock. McGill-Queen's University Press.

Becker, G. (2000). The elusive embryo: How women and men approach new reproductive technologies. University of California Press.

Bleikli, I., Goggin, M.L., \& Rothmayr, C. (Eds.). (2004). Comparative biomedical policy: Governing assisted reproductive technologies. Routledge.

Castro-Vàzquez, G. (2017). Intimacy and reproductive in contemporary Japan. Routledge.

Engeli, I., \& Allison, C.R. (2017). Governing new reproductive technologies across Western Europe: The gender dimension. In M. Lie, \& N. Lykke (Eds.), Assisted reproduction across borders: Feminist perspectives on normalizations, disruptions and transmissions. Routledge.

Franklin, S. (1997). Embodied progress: A cultural account of assisted conception. Routledge.

Gingrich, A., \& Fox, R.G. (Eds.). (2002). Anthropology, by comparison. Routledge.

Haraway, D.J. (1988). Situated knowledges. The science question in feminism and the privilege of partial perspective. Feminist Studies, 14(3), 575-599. https:// doi.org/10.2307/3178066

Harper, J.C., Kennett, D., \& Reisel, D. (2016). The end of donor anonymity: How genetic testing is likely to drive anonymous gamete donation out of business. Human Reproduction, 31(6), 1135-1140. https://doi.org/10.1093/humrep/dew065

Inda, J.X., \& Rosaldo, R. (Eds.). (2008). The anthropology of globalization: A reader. Blackwell Publishing.

Inhorn, M., \& van Balen, F. (2002). Infertility around the globe: New thinking on childlessness, gender, and reproductive technologies. University of California Press. 
Japanese Institution for Standardizing Assisted Reproductive Technology. (2021). Background of IVF implementation. https://jisart.jp/about/external/how/

Jasanoff, S. (2005). Designs on nature: Science and democracy in Europe and the United States. Princeton University Press.

Katagiri, Y. (2020). Shikija no me’Zentai no yaku 6\% ni noboru seishoku iryō no gennjyō [Current status of assisted reproductive technology, which accounts for about $6 \%$ of all births]. Japanese Medical Journal, 5014, 65. https://www. jmedj.co.jp/journal/paper/detail.php?id=14665

Kinjō, K. (2012). Dai 2 shō Haigushi teikyū [Chapter 2 Gamete donation]. In N. Suganuma, \& S. Morinaga (Eds.), Sirizu Seimei rinrigaku: Seishoku iry [The Japanese Bioethics Series: Reproductive medicine] (pp. 24-44). Maruzen Publishing.

Kobayashi, T., Sugiura, N., \& Hatano, D. (2020, 7 October). Internet sperm donations increase, along with dangers. The Asahi Shimbun. http://www.asahi.com/ ajw/articles/13795940

Kurahashi, K. (2017). Dansei funin to dansei sei-‘Oi’ to i.u. shiten wo yomu [Male infertility and masculinity: From the perspective of 'ageing']. In H. Yui, \& Y. Matsubara (Eds.), Studies for inclusive Society 16. Reproduction: Population policy and gender. Ritumeikan University.

Lie, M., \& Lykke, N. (Eds.). (2017). Assisted reproduction across borders: Feminist perspectives on normalizations, disruptions and transmissions. Routledge.

Lock, M.M. (1993). Encounters with aging: Mythologies of menopause in Japan and North America. University of California Press.

Mehrabi, T. (2017). Matters of donation and preserved relations: Co-construction of egg donation and family structures in Iran. In M. Lie, \& N. Lykke (Eds.), Assisted reproduction across borders: Feminist perspectives on normalizations, disruptions and transmissions (pp. 189-204). Routledge.

Melhuus, M. (2012). Problems of conception: Issues of law, biotechnology, individuals and kinship. Berghahn.

Minami, T. (2016). Legislation toward allowing all donor-conceived offspring the right to know their origin: The cases of Japan and Victoria, Australia. Journal of Philosophy and Ethics in Health Care and Medicine, 10, 13-22.

Osaki, T. (2020, 27 December). 'DM if interested': Sperm donors in Japan operate in a grey zone. Japan Times. https://www.japantimes.co.jp/news/2020/12/27/ national/science-health/japan-sperm-donors/

Ravn, M.N. (2005). A matter of free choice? Some structural and cultural influences on the decision to have or not to have children in Norway. In C.B. Douglass (Ed.). Barren states: The population 'implosion' in Europe (pp. 29-47). Berg.

Robertson, H. (2018, 1 October). Sperm shortages force Tokyo hospital to end donor insemination. Bionews 969. https://www.bionews.org.uk/page_138777

Score of life (2014, 27 April). Egg donation, unsuccessful legal development, women traveling abroad seeking 'eggs' [Original title: Jinsei no gakufu (3) 'Ranshi teikyō' Susumanu hōseibi, 'Ranshi' motomete Kaigai he wataru joseitachi]. Sankei News. https:/www.sankei.com/west/print/140427/wst1404270075-c.html

Shirai, C. (2019). Genetic ties and affinity: Longitudinal interviews on two mothers' experiences of egg donation in Japan. East Asian Science, Technology and society: An International Journal, 12, 299-315.

Spilker, K., \& Lie, M. (2007). Gender and bioethics intertwined: Egg donation 
within the context of equal opportunities. European Journal of Women's Studies, 14(4), 327-340.

Takeya, K., (2008). Funin wo meguru shakai reikshiteki haikei to sono gensetsu [Social historical background and discourse surrounding infertility]. Department Bulletin Paper of Faculty of Education, 11, 25-32.

Tsuge, A. (2005). How society responds to desires of childless couples: Japan's position on donor conception. Pp Bulletin of Institute of Sociology and Social Work, 35, 21-34.

Van Dyck, J. (1995). Manufacturing babies and public consent: Debating the new reproductive technologies. Macmillan.

Wernick, A. (2020, 23 November). Japanese bill defines parenthood in fertility treatment cases. Bio News 1073. https://www.bionews.org.uk/page_153368\#: :text=A\%20bill $\% 20$ submitted $\% 20$ to $\% 20$ Japanese,use $\% 20$ sperm \%20and $\% 20$ egg $\% 20$ donation

Wong, A.E. (2008). Relocating East and West: UNESCO's major project on the mutual appreciation of Eastern and Western cultural values. Journal of World History, 19(3), 349-374.

Yamamoto, N., Hirata, T., Izumi, G., Nakazawa, A., Fukuda, S., Neriishi, K., Arakawa, T., Takamura, M., Harada, M., Hirota, Y., Koga, K., Wada-Hiraike, O., Fujii, T., Irahara, M., \& Osuga, Y. (2018). A survey of public attitudes towards third-party reproduction in Japan in 2014. PLOS ONE, 13(10). https:// doi.org/10.1371/journal.pone.0198499

Yui, H. (2016). Taigai jusei no rinshō ōyō to Nihon jusei chakushō gakkai no setsuritsu. [Clinical application of in vitro fertilization and establishment of Japan Society of Fertilization and Implantation]. Journal of History of Science, Japan, 55(278), 118-132. 